\title{
Advancement of Gallium and Gallium-Based Compounds as Antimicrobial Agents
}

\author{
Fupeng Li, Fengxiang Liu *, Kai Huang * and Shengbing Yang * \\ Shanghai Key Laboratory of Orthopaedic Implants, Department of Orthopaedic Surgery, Shanghai Ninth People's Hospital, \\ Shanghai Jiao Tong University School of Medicine, Shanghai, China
}

OPEN ACCESS

Edited by:

Jenneke Klein-Nulend, Academic Centre for Dentistry

Amsterdam, Netherlands

Reviewed by: Muhammad Aqeel Bhutto, University of Sindh, Pakistan Javier Alberto Garza Cervantes, Autonomous University of Nuevo León, Mexico

${ }^{*}$ Correspondence: Fengxiang Liu liu_fengxiang@126.com Kai Huang kaihuang@shsmu.edu.cn Shengbing Yang shengbingyang@shsmu.edu.cn

\section{Specialty section: This article was submitted to Biomaterials, \\ a section of the journal Frontiers in Bioengineering and Biotechnology \\ Received: 02 December 2021 Accepted: 13 January 2022 Published: 04 February 2022}

Citation:

Li F, Liu F, Huang K and Yang S (2022) Advancement of Gallium and Gallium-

Based Compounds as Antimicrobial Agents.

Front. Bioeng. Biotechnol. 10:827960. doi: 10.3389/fbioe.2022.827960
With the abuse and misuse of antibiotics, antimicrobial resistance has become a challenging issue in the medical system. latrogenic and non-iatrogenic infections caused by multidrug-resistant (MDR) pathogens pose serious threats to global human life and health because the efficacy of traditional antibiotics has been greatly reduced and the resulting socio-economic burden has increased. It is important to find and develop non-antibiotic-dependent antibacterial strategies because the development of new antibiotics can hardly keep pace with the emergence of resistant bacteria. Gallium (III) is a multi-target antibacterial agent that has an excellent antibacterial activity, especially against MDR pathogens; thus, a gallium (III)-based treatment is expected to become a new antibacterial strategy. However, some limitations of gallium ions as antimicrobials still exist, including low bioavailability and explosive release. In recent years, with the development of nanomaterials and clathrates, the progress of manufacturing technology, and the emergence of synergistic antibacterial strategies, the antibacterial activities of gallium have greatly improved, and the scope of application in medical systems has expanded. This review summarizes the advancement of current optimization for these key factors. This review will enrich the knowledge about the efficiency and mechanism of various gallium-based antibacterial agents and provide strategies for the improvement of the antibacterial activity of gallium-based compounds.

Keywords: gallium (Ga(III)), antibacterial, iron matabolism, optimization, bioavailability

\section{INTRODUCTION}

The emergence of drug-resistant bacteria has greatly reduced the therapeutic effect of traditional antibiotics, posing a great challenge to the global medical systems and requiring the research and development of novel non-antibiotic-dependent antibacterial strategies (Roope et al., 2019) to combat drug resistance. Gallium is a semi-metallic element whose citrate buffered nitrate form was approved by the United States Food and Drug Administration (FDA) for clinical use in the treatment of malignant tumor-related hypercalcemia and autoimmune diseases in 2003 (Leyland-Jones, 2003). Noteworthy, its antibacterial effect has gradually attracted attention in recent years.

In 1931, Levaditi et al. (1931) found that intravenous injection of gallium tartrate could eliminate both syphilis in rabbits and Trypanosoma evansi in mice. Moreover, Yukihiro et al. (Britigan et al., 2000; Kaneko et al., 2007; Lessa et al., 2012) found that gallium has a strong killing effect on Pseudomonas aeruginosa, a multi-drug resistant opportunistic pathogen that is also the main pathogenic bacterium responsible for respiratory failure in patients with pulmonary cystic 
TABLE 1 | Summary of the use of gallium and gallium-compounds as antimicrobial agents.

Optimization strategies

Gallium and gallium-based compounds
Antimicrobial effects

References coordination compound gallium citrate, gallium maltolate, gallium tartrate, tris(8-quinolinolato) gallium (III) (KP46), and gallium (III) complexes of a-N-heterocyclic thiosemicarbazones

$\mathrm{Ga}_{2} \mathrm{~L}_{3}$ (bpy) $)_{2},\left(\mathrm{~L}=2,2^{\prime}\right.$-bis(3-hydroxy1,4naphthoquinone); bpy = 2,2'-bipyridine)

$\mathrm{GaMe}_{2}(\mathrm{~L})$ and $\mathrm{Ga}(\mathrm{Me})_{2} \mathrm{~L}$

$\begin{array}{ll}\begin{array}{l}\text { nanomaterial- } \\ \text { based vehicles }\end{array} & \text { Lipo-Ga-GEN } \\ & \text { gallium-NAC } \\ & \\ & \text { gallium-containing siderophores and heme } \\ & \text { analogues: desferoxamine-gallium, Ga- } \\ & \text { protoporphyrin IX, Ga-deuteroporphyrin, Ga- } \\ & \text { mesoporphyrin, Ga-hematoporphyrin, Ga- } \\ & \text { octaethylporphyrin, and Ga-porphine } \\ & \text { ciprofloxacin-siderophore }\end{array}$

bioresponsive antibacterial nanomaterials based on gallium (III) and iron (III) cross-linked polysaccharide materials improved bioavailability of gallium alloys and scaffold composites

layered double hydroxide

Synergistic strategies
Lin et al. (2021), Best et al. (2020)

Ga-doped titanium alloys

Ga-doped magnesium alloys eutectic gallium-indium alloys

bioglasses doped with gallium

gallium-doped zinc borate bioactive glass

phosphate glass, hydroxyapatite, PCL and hydrogel, collagen, poly (4-hydroxybutyrate), silk fibroin, Ca titanate

gallium (Ga)-strontium (Sr) layered double hydroxides

gallium (Ga)-zinc (Zn) layered double hydroxides

ciprofloxacin, colistin, meropenem, and tobramycin

tetracycline

poly (ethylene glycol)-desferrioxamine/gallium (PEG-DG) conjugates

a xenosiderophore-conjugated cationic random copolymer

improved solubility and not poor bactericidal Bonchi et al. (2014), Piatek et al. (2020), Lessa effects on drug-resistant Gram-negative and et al. (2012)

Gram-positive bacteria, including $P$. aeruginosa, Acinetobacter baumannii, $M$. tuberculosis, and methicillin-resistant Staphylococcus aureus exert bactericidal effects on drug-resistant $P$. Wang et al. (2021b) aeruginosa and $S$. aureus in an ironcontaining environment improved antibacterial activity than Duffin et al. (2020) quinolinolate alone

improved antibacterial activity than the corresponding drugs without liposomes more gallium ions were deposited in $P$. aeruginosa cells in the gallium-NAC treatment group than in the traditional gallium citrate treatment group not all siderophores combined with an antibacterial agent show increased antibacterial activity. Ga-protoporphyrin IX showed the best antibacterial effect

decreased uptake of gallium and antibacterial potency compared to ciprofloxacin alone both in iron replete and deplete conditions

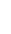

\section{Halwani et al. (2008) \\ Young et al. (2019)}

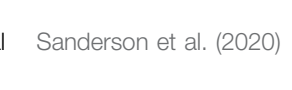

20)


TABLE 1 | (Continued) Summary of the use of gallium and gallium-compounds as antimicrobial agents.

\begin{tabular}{|c|c|c|c|}
\hline $\begin{array}{l}\text { Optimization } \\
\text { strategies }\end{array}$ & $\begin{array}{l}\text { Gallium and gallium-based } \\
\text { compounds }\end{array}$ & Antimicrobial effects & References \\
\hline & a gallium-chitosan complex & $\begin{array}{l}\text { improved antibacterial activity than that of } \\
\text { single chitosan }\end{array}$ & Akhtar et al. (2020) \\
\hline & ciprofloxacin-functionalized desferrichrome & $\begin{array}{l}\text { improved antibacterial activity than that of } \\
\text { ciprofloxacin alone }\end{array}$ & Pandey et al. (2019) \\
\hline & metal ions & $\begin{array}{l}\text { silver ions, zinc ions, Cd, Se, and Ga had } \\
\text { good synergistic effects }\end{array}$ & $\begin{array}{l}\text { Aziz (2019), Pormohammad and Turner (2020); } \\
\text { Vaidya et al. (2019), Yoon et al. (2006) }\end{array}$ \\
\hline & $\begin{array}{l}\text { gallium-substituted hemoglobin combined with } \\
\text { Ag nanoparticles }\end{array}$ & improved antibacterial activity & Morales-de-Echegaray et al. (2020) \\
\hline & $\begin{array}{l}\text { gallium-porphyrin, gallium-substituted } \\
\text { hemoglobin, phthalocyanine, indocyanine green } \\
\text { (ICG), hollow titanium dioxide nanotubes and } \\
\text { gallium ions }\end{array}$ & improved antibacterial activity & $\begin{array}{l}\text { Morales-de-Echegaray et al. (2020); Shisaka et al. } \\
\text { (2019), Xie et al. (2021), Rahimnejad Yazdi et al. } \\
\text { (2018) }\end{array}$ \\
\hline & nitrates and gallium ions & $\begin{array}{l}\text { induce antibacterial activity against } P \text {. } \\
\text { aeruginosa under both aerobic and } \\
\text { anaerobic conditions }\end{array}$ & Zemke et al. (2020) \\
\hline & graphene foam and gallium ions & improved antibacterial activity & Slate et al. (2021) \\
\hline
\end{tabular}

fibrosis. The ideal bactericidal effect of gallium ions can be achieved even at micromolar concentration levels. In addition, gallium at such low concentrations can remove the biofilm formed by $P$. aeruginosa, which is difficult to eliminate by traditional antibiotics. Furthermore, Choi et al. (2017, 2019) demonstrated that gallium also has bactericidal effects against common drug-resistant bacteria, such as Mycobacterium tuberculosis, Klebsiella pneumoniae, and other Gram-negative bacteria.

Currently, it is believed that the mechanism underlying the gallium antibacterial effect is related to gallium uptake by bacteria as an iron mimic. Considering that gallium is a redox inert metal that cannot be reduced under physiological conditions, galliumsubstituted enzymes cannot exert the functions of the corresponding iron-dependent enzymes, which are indispensable for bacterial proliferation; thus, iron metabolism is disturbed, leading to bacterial death (Kelson et al., 2013). Iron is an indispensable nutrient for bacterial proliferation, especially for bacteria that establish infections in vivo. Therefore, it is difficult for bacteria to evolve resistance to gallium by reducing uptake, because it would reduce iron uptake as well. Consequently, it is believed that galliumbased compounds may become the next generation of antibiotics because of their scavenging effect on resistant bacteria.

Although gallium has definite antibacterial effects, it is almost completely hydrolyzed into insoluble hydroxide under physiological conditions. Therefore, it is difficult to release adequate quantities of gallium (III) to play an antibacterial role due to its extremely low bioavailability (Bonchi et al., 2014). In contrast, the prevention and treatment of iatrogenic infections caused by implants or internal incisions requires the maintenance of antimicrobial agent concentrations above the minimum inhibitory concentration (MIC) at the infection foci, and the explosive release of an element in a short period of time would hardly meet the clinical needs (Zhang et al., 2015; Shao et al., 2016; Ning et al., 2018).

Besides, in contrast with the treatment of respiratory infections, implant-related anti-infective materials have to be

\begin{tabular}{lcc}
\hline TABLE 2 | Similarities between gallium and iron ions. & \\
\hline & Gallium (III) & Iron (III) \\
\hline Octahedral ion radius & $0.620 \AA$ & $0.645 \AA$ \\
Tetrahedral ion radius & $0.47 \AA$ & $0.49 \AA$ \\
lonization potential & $64 \mathrm{eV}$ & $54.8 \mathrm{eV}$ \\
lonization affinity & $30.71 \mathrm{eV}$ & $30.65 \mathrm{eV}$
\end{tabular}

implanted in vivo in the form of scaffolds, requiring good biomechanical properties and releasing antibacterial agents in a sustained manner. Finally, a combination of drugs with different antibacterial mechanisms could produce stronger synergistic antibacterial effects than a single antibacterial component; this has become a research hotspot. Various combinations of gallium ions and clinically applied antibiotics or other non-antibiotic antimicrobial agents are expected to potentiate the antibacterial effect of gallium (III) and enable the traditional antibiotics to be applied in the treatment of drug-resistant bacteria through synergistic effects (GarciaContreras et al., 2013). This review summarizes the abovementioned methods for improving the antibacterial effect of gallium, explores the putative antibacterial mechanism of gallium, and provides ideas for the development of novel gallium-based antibacterial strategies and for promoting the clinical transformation of gallium-based drugs (Table 1).

\section{BIOCHEMICAL PROPERTIES OF GALLIUM AND IRON IONS}

Gallium is an element of group IIIA of the periodic table, with an atomic number of 31 and a molecular weight of $69.72 \mathrm{~g} / \mathrm{mol}$. The chemical behavior of gallium is close to that of $\mathrm{Fe}$ (III) in terms of its electrical charge, ion diameter, coordination number, electron affinity, tendency to form ionic bonds, ionization potential, and 


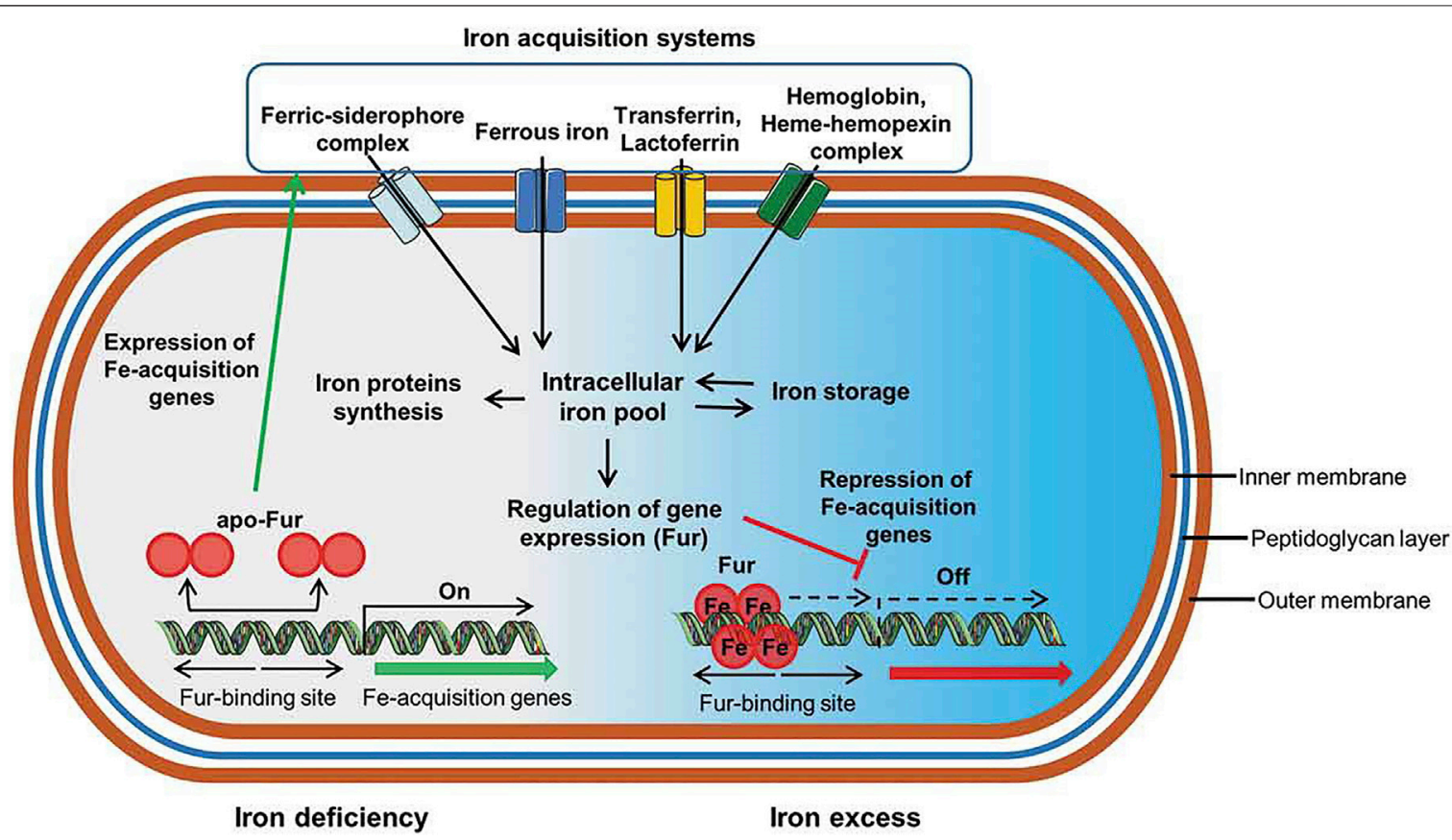

FIGURE 1 | Schematic representation of critical iron acquisition mechanisms and pathways in bacteria. Both Gram-negative and Gram-positive bacteria have evolved multiple sophisticated systems to acquire iron from the environment, including trivalent iron containing siderophores, hemes, heme proteins, heme analogues, and transferrin/lactoferrin. Due to the similarity between gallium and iron, the above pathways are also suitable for gallium transport, providing the possibility of targeted therapy for gallium (Seyoum et al., 2021).

electron configuration. The exact parameters are summarized in Table 2. Another similarity between these elements is the extensive hydrolysis that occurs in neutral aqueous solutions, with the consequent formation of various hydroxide species, such as $\mathrm{Ga}(\mathrm{OH})_{4}$ and $\mathrm{Ga}(\mathrm{OH})_{3}$, for that $\mathrm{Ga}(\mathrm{III})$ ions, having low polarization and a small size, are hard acids with high affinity for hydroxide ions (Nielsen et al., 2021). Although gallium hydroxide precipitates under physiological conditions, it is soluble under acidic or alkaline conditions. When the $\mathrm{pH}$ of the solution changes from low to high, gallium hydroxide changes from a dissolved state to a precipitated state in the form of $\mathrm{Ga}(\mathrm{OH})_{3}$ and then back to a dissolved state as $\mathrm{Ga}(\mathrm{OH})_{4}$. However, it is worth noting that gallium is a redox inert element that cannot be reduced to $\mathrm{Ga}(\mathrm{II})$ under physiological conditions (Centola et al., 2020).

The proteins responsible for iron transport in vivo, such as transferrin and lactoferrin, can also bind stably with gallium. However, gallium-transporter complexes are more sensitive to acidic $\mathrm{pH}$ than iron-transporter complexes, and strong dissociation of gallium ions can occur at pH 6.1 (Bonchi et al., 2014).

\section{ANTIBACTERIAL MECHANISM OF GALLIUM IONS}

\subsection{Iron Uptake}

Iron is an essential nutrient for the survival and proliferation of both bacteria and cells; it is a universal cofactor of oxidoreductases that participates in a variety of critical metabolic pathways in vivo, such as DNA synthesis, electron transfer, and anti-oxidative stress (Andrews et al., 2003). As a result, bacteria that colonize a host and establish an infection require more iron than free living bacteria to maintain their fundamental nutrient needs for growth. Due to the low bioavailability of iron in the body, bacteria have evolved a complicated iron uptake mechanism, whereby continuous evolution and mutation, to compete with cells and other microorganisms in the body for iron to survive and reproduce. At present, most studies believe that bacteria mainly obtain iron from the outside world in three ways (Figure 1): 1) siderophore-based systems, 2) heme/ hemeprotein-based systems, and 3) transferrin and lactoferrin-based systems (Kelson et al., 2013).

Siderophores (Wilson et al., 2016) are small molecules secreted by microorganisms; siderophores can specifically recognize and bind to ferric ions from the host or other exogenous sources. In addition, bacteria simultaneously secrete heme carriers to capture hemes and heme analogues in the host. Heme is an important prosthetic group of human heme proteins, such as hemoglobin and myoglobin, which are responsible for oxygen transport. Kelson et al. (2013) systematically summarized the siderophores and heme carriers secreted by common pathogens. For example, pyoverdine and pyochelin, two types of siderophores secreted by $P$. aeruginosa, are critical for iron acquisition by this bacterium. 
Bacteria can acquire iron depending on siderophores or heme carriers, but bacteria can also directly interact with iron sources, such as iron or hemes, and transport them into the cell through membrane receptors. Gram-positive bacteria specifically recognize the surrounding iron or iron-containing siderophores and hemes through receptors on the cytoplasmic membrane and then transport them to the cytoplasm where trivalent iron is dissociated from the complex and reduced to divalent iron for further use. In Gram-negative bacteria, the iron source is first recognized by an outer membrane receptor and then transported into the periplasm where it may enter the cell through the plasma membrane.

\subsection{Iron Contender}

Owing to the extremely similar biochemical characteristics of gallium and iron, it is difficult for biological systems to distinguish between gallium (III) and iron (III) and their corresponding compounds, such as iron protoporphyrin and gallium protoporphyrin; this is also the basis for the specific uptake of gallium by bacteria according to the above-mentioned pathways. Therefore, gallium can be used as an antagonist of iron to competitively bind to irondependent proteins, thus affecting the function and activity of related enzymes. In summary, gallium could be firmly bound to the siderophores that should be combined with iron, reducing the amount of iron obtained, and gallium complexes enter the bacterial cells as Trojan horses, but cannot undergo redox, interrupting the normal enzyme metabolism.

\subsection{Disturbance of Iron Metabolism}

Considering that gallium (III) cannot be reduced to divalent gallium under physiological conditions, when an enzyme that regularly has iron as a cofactor replaces it for gallium, its activity is affected, and its related biochemical processes are interrupted. It is believed that the inhibition of bacterial activity caused by iron metabolism disorders is mainly due to the inactivation of deoxynucleotide reductase. However, other important factors include the electron transfer, Krebs cycle, and protein synthesis. Ribonucleotide reductase (Kircheva \& Dudev, 2021) is an indispensable ironcontaining enzyme that participates in DNA replication and is essential for bacterial proliferation.

Recent studies have shown that oxidative stress caused by iron metabolism disorders plays a pivotal role in the antibacterial effect of gallium. Interestingly, it has been shown that the overexpression of NADPH-producing enzymes can counteract the oxidative stress evoked by gallium (Beriault et al., 2007). Zeng et al. (2021) also found that Escherichia coli strains with mutations in the evgS gene, encoding ROS detoxification enzymes, developed tolerance to gallium nitrate. Besides, the antibacterial effect of gallium ions on aerobic bacteria is better than that on anaerobic bacteria, which also indicates that reactive oxygen may be involved in the antibacterial mechanism of gallium (Zemke et al., 2020). The molecular mechanism of the antibacterial action of gallium ions remains to be further explored.

In addition to inhibiting bacterial proliferation by disturbing the activity of iron-containing enzymes such as deoxyribonucleotide reductase, gallium ions can reduce the production of virulence factors. Among virulence factors, biofilm formation is a crucial mechanism for multidrug resistance (Zhang et al., 2021). Bacteria secrete extracellular polymers to protect them from external antibiotics and the host immune system. In addition, the phenotypes of bacteria inhabiting biofilms are altered compared to that of planktonic bacteria. The proliferation rate tends to be lower, and the sensitivity to antibiotics is significantly reduced. Kang and Kirienko (2018) demonstrated that iron is indispensable for the formation of biofilms. Inactivation of pyoverdine, a key siderophore for $P$. aeruginosa, prevents biofilm formation; however, supplementation with ferric citrate can restore this ability. Therefore, gallium, as an iron antagonist, can affect the virulence of bacteria by reducing the iron content. A proteomic analysis suggested that gallium ions could reduce the expression abundance of quorum-sensing and swarming motility related proteins in $P$. aeruginosa; these proteins play a fundamental role in bacterial virulence and dissemination (Piatek et al., 2020).

\section{OPTIMIZATION OF GALLIUM-BASED COMPOUNDS}

\subsection{Development of Gallium-Based Clathrates}

Gallium ions are highly hydrolyzable under physiological conditions, and trivalent gallium ions are almost completely hydrolyzed into insoluble hydroxides in the body, leading to extremely low bioavailability. Consequently, there are few gallium ions entering bacterial cells in vivo to play an antibacterial role. At present, the problem of precipitation caused by the hydrolysis of gallium is mainly solved by chelating various organic ligands with gallium to form complexes with increased water solubility. The precipitation of hydroxides may be prevented by surrounding the gallium cation with an appropriate ligand sphere, rendering it stable to hydrolysis. Furthermore, the pharmacokinetics of galliumbased drugs is closely related to their coordination chemistry, and different ligands have a profound impact on the water solubility of gallium-based drugs. Currently, mature gallium salts and gallium-based coordination compounds, such as gallium nitrate, gallium chloride, gallium citrate, gallium maltolate, gallium tartrate, tris(8-quinolinolato) gallium (III) (KP46), and gallium (III) complexes of a-Nheterocyclic thiosemicarbazones, with improved solubility and not poor bactericidal effects on drug-resistant Gramnegative and Gram-positive bacteria, including $P$. aeruginosa, Acinetobacter baumannii, M. tuberculosis, and methicillin-resistant Staphylococcus aureus, are being tested. 

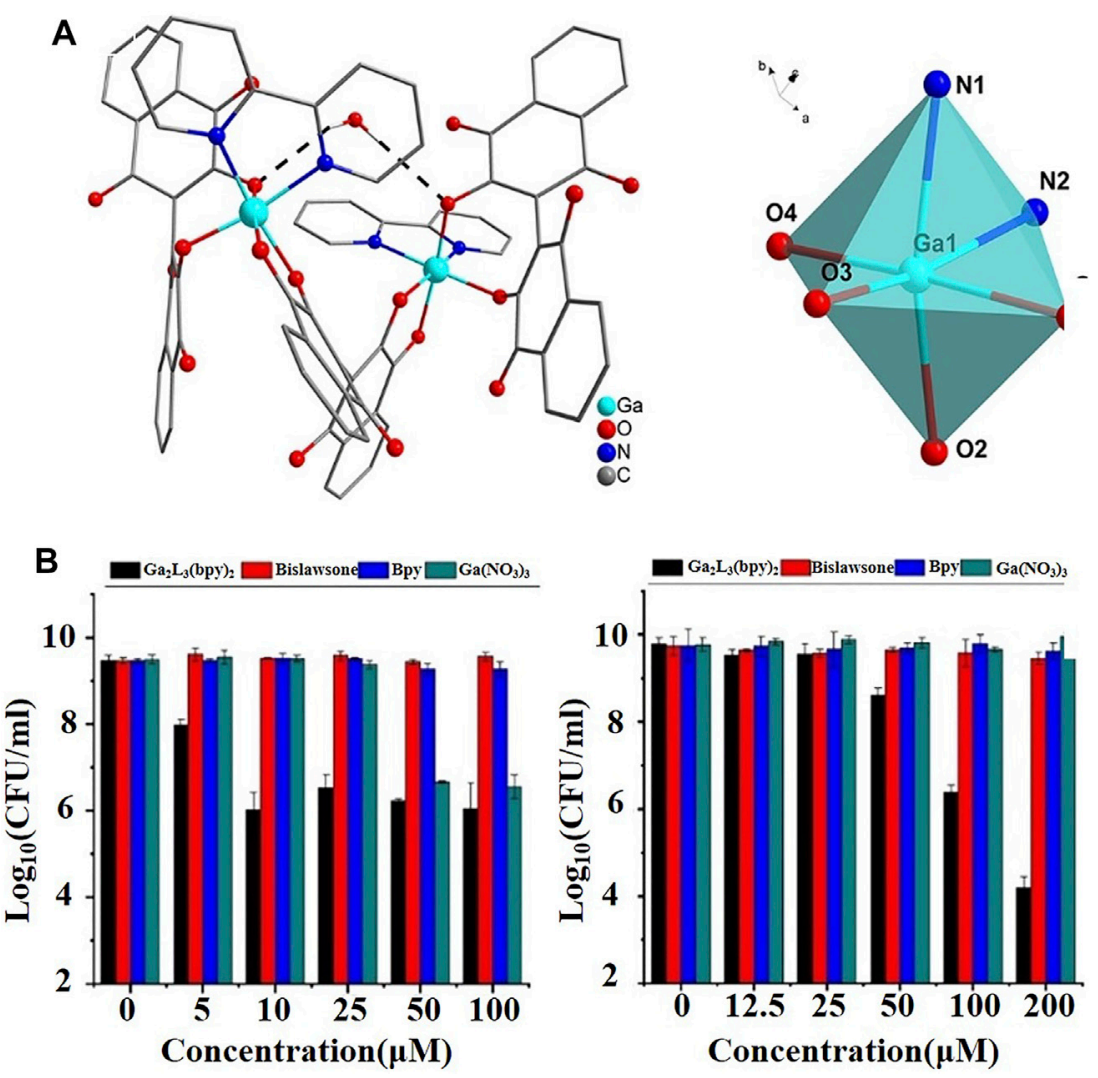

FIGURE 2 | (A) Molecular structure of $\left[\mathrm{Ga}_{2} \mathrm{~L}_{3}(\mathrm{bpy})_{2}\right] \cdot \mathrm{H} 2 \mathrm{O}$ as determined by single-crystal X-ray structure analysis (left), and schematic representation of the coordination environment of the Ga(III) ion (right) (Wang et al., 2021b). (B) Antibacterial effect of [Ga $\mathrm{G}_{3}(\mathrm{bpy})_{2}$ ] on drug-sensitive P. aeruginosa ATCC 15692 (left) and drug-sensitive S. aureus ATCC 6538 (right) compared with those of gallium nitrate, bpy, and bislawsone (Wang et al., $2021 \mathrm{~b})$.

Bonchi et al. (2014) systematically summarized the pharmacological properties and antibacterial activities of the gallium salts and gallium-based complexes mentioned above. Among them, gallium maltoate, as a second-generation gallium-based coordinated complex, may be used in an oral or topical way with obviously improved bioavailability of gallium ions compared to that of gallium nitrate. Piatek et al. (2020), using quantitative proteomics, further revealed that gallium maltoate exerted antibacterial effects by inhibiting the quorum-sensing system in $P$. aeruginosa. Similar to gallium maltoate, KP46 was also designed to improve the oral bioavailability of gallium ions. Thiosemicarbazones, antibacterial and antitumor drugs, can also be applied as ligands to form complexes with gallium ions (Enyedy et al., 2012). Lessa et al. (2012) demonstrated that gallium-based compounds coordinated with 2-formylpyridine-, 2acetylpyridine-, and 2-benzoylpyridine-derived thiosemicarbazones not only potentiated the antibacterial activity of gallium ions due to their increased bioavailability, but also improved the antibacterial activity and spectrum of thiosemicarbazones. New gallium complexes have also been developed with the continuous discovery of ligands. Wang et al. (2021b) synthesized a lipophilic ligand, $\mathrm{Ga}_{2} \mathrm{~L}_{3}$ (bpy $)_{2}, \quad\left(\mathrm{~L}=2,2^{\prime}\right.$-bis(3-hydroxy1,4naphthoquinone); bpy $=2,2^{\prime}$-bipyridine) (Figure $\mathbf{2 A}$ ), which had excellent bactericidal effects on drug-resistant $P$. aeruginosa and $S$. aureus in an iron-containing environment, with MIC of 10 and $100 \mu \mathrm{M}$, respectively (Figure 2B). The antibacterial effect was superior to that of gallium alone. More interestingly, the lipophilic gallium ligand delayed the emergence of bacterial resistance. Duffin et al. (2020) synthesized a series of eight alkyl gallium complexes of general formulae $\left[\mathrm{GaMe}_{2}(\mathrm{~L})\right]$ and $\left[\mathrm{Ga}(\mathrm{Me})_{2} \mathrm{~L}\right]$ to increase the release of gallium and promote a reaction with transferrin and lactoferrin. The antibacterial activity of alkyl gallium (III) quinolinolate was three times that of quinolinolate alone. It is worth noting that the category and quantity of alkyl gallium (III) quinolinolate had a certain influence on the lipid solubility of the complex, providing a reference for the development of new antibacterial galliumbased complexes. In addition, gallium-based complexes with tranexamic acid and pyrophosphate as ligands have achieved 
A
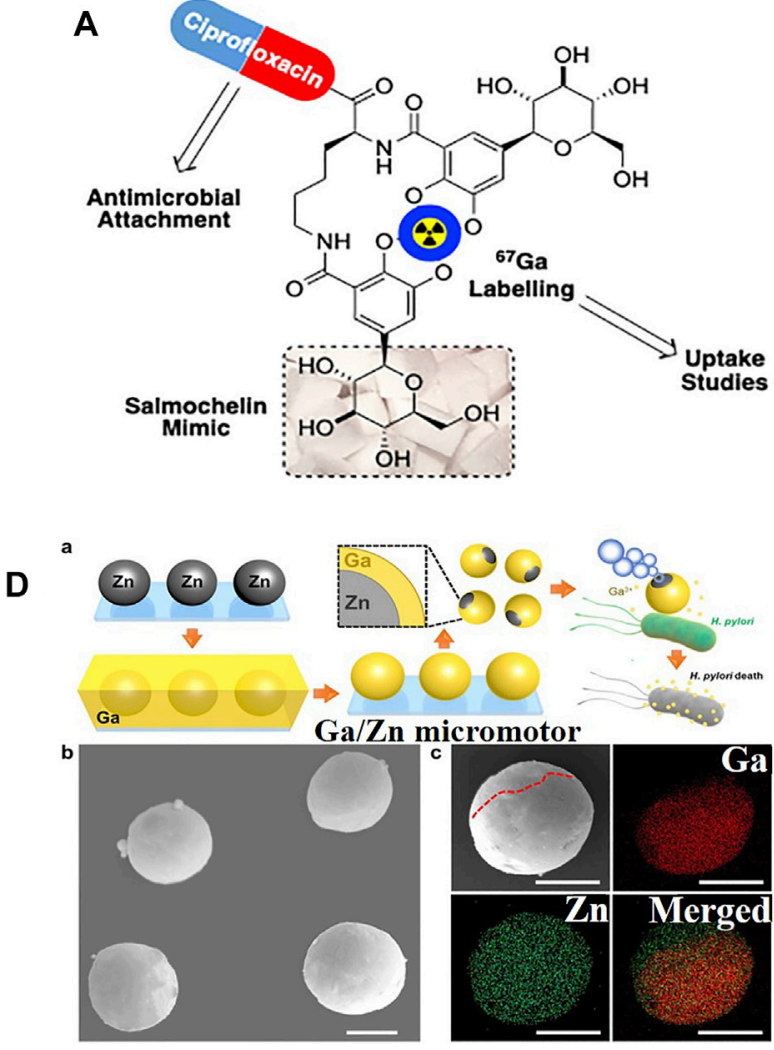

B
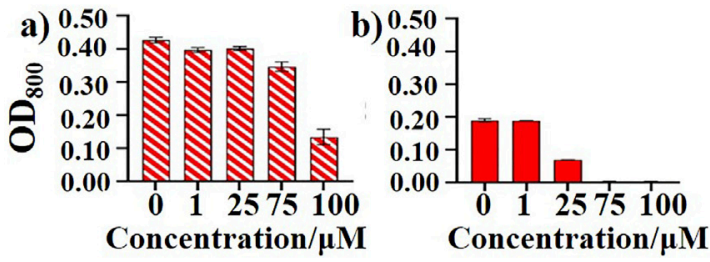

C

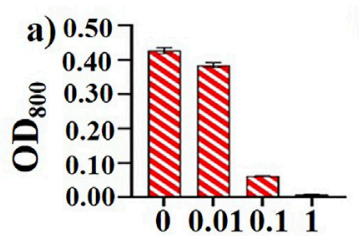

E

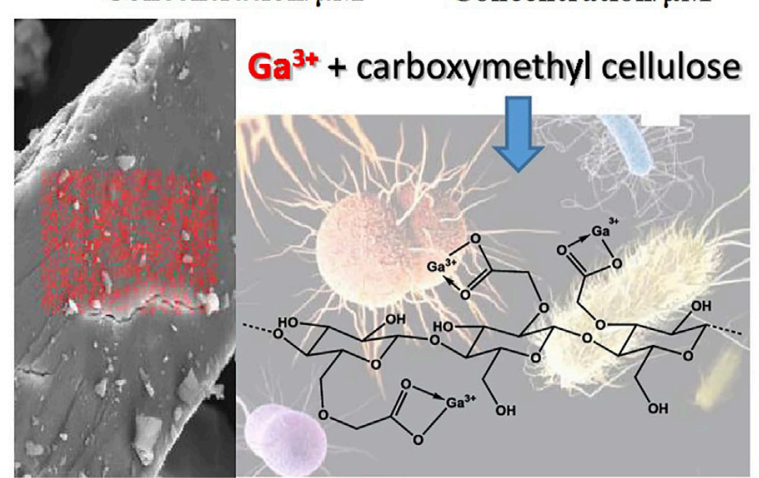

FIGURE 3 | (A) Schematic representation of a ciprofloxacin-siderophore Trojan horse antimicrobial (Sanderson et al., 2020). (B,C) Growth status of E. coli K12 (BW25113) in the presence of (B) ciprofloxacin-siderophores and (C) ciprofloxacin after 48 h with (a) sufficient iron levels or (b) scarce iron (Sanderson et al., 2020). (D) Schematic representation of the synthesis and antibacterial mechanism of Janus Ga/Zn micromotors and their characterization (Lin et al., 2021). (E) Scheme of gallium molecules encapsulated by carboxymethyl cellulose (CMC) (Best et al., 2020).

great success as antitumor agents, given the similarity of bacterial and tumor metabolisms (El-Habeeb and Refat, 2019). Their application in the field of antibacterial therapy is worthy of further study (Greenfield et al., 2019).

\subsection{Advancement in the Development of Nanomaterial-Based Vehicles for Loading Gallium lons}

The emergence of diverse nanomaterials provides an excellent platform for loading gallium ions. On the one hand, the ideal nanomaterial surface-capping agent could improve the biocompatibility of gallium ions and increase the therapeutic window range; on the other hand, it could effectively reduce the hydrolysis of gallium (III), thus, releasing more gallium ions at the infection site. Halwani et al. (2008) used liposomes as carriers to encapsulate and transport gallium ions and improve their bioavailability by taking advantage of the lipophilic characteristics of liposomes. The complexes demonstrated excellent antimicrobial activity against $P$. aeruginosa and the corresponding biofilms compared to $\mathrm{Ga}\left(\mathrm{NO}_{3}\right)_{3}$ alone. Lipo-Ga-GEN, liposomes carrying both gallium ions and gentamicin $(0.6 \mu \mathrm{M}$ for $\mathrm{Ga}$ and $8 \mathrm{mg} / \mathrm{L}$ for $\mathrm{GEN}$, respectively), inhibited bacterial growth completely, while other formulations failed to achieve the same effect at the same drug concentrations. In addition, Lipo-Ga-GEN, LipoGa (liposomes carrying gallium ions only), and Lipo-GEN (liposomes carrying gentamicin only) exhibited better antibacterial activities than the corresponding drugs without liposomes (Halwani et al., 2008), providing another way to improve the bioavailability of gallium. Similar to liposomes, N-acetyl-cysteine (NAC), a thiolsubstituted derivative of the amino acid L-cysteine, has been used as a surface-capping agent for gallium because of its excellent biocompatibility and water solubility (Young et al., 2019). The amount of gallium ions released by the NAC-coated gallium particles was much higher than that of the gallium particles without NAC coating. Noteworthy, more gallium ions were deposited in $P$. aeruginosa cells in the gallium-NAC treatment group than in the traditional gallium citrate treatment group, indicating that NAC promoted the absorption of gallium ions.

In addition, the construction of gallium-containing siderophores and heme analogues, taking advantage of the iron uptake pathway, provides another strategy for the 

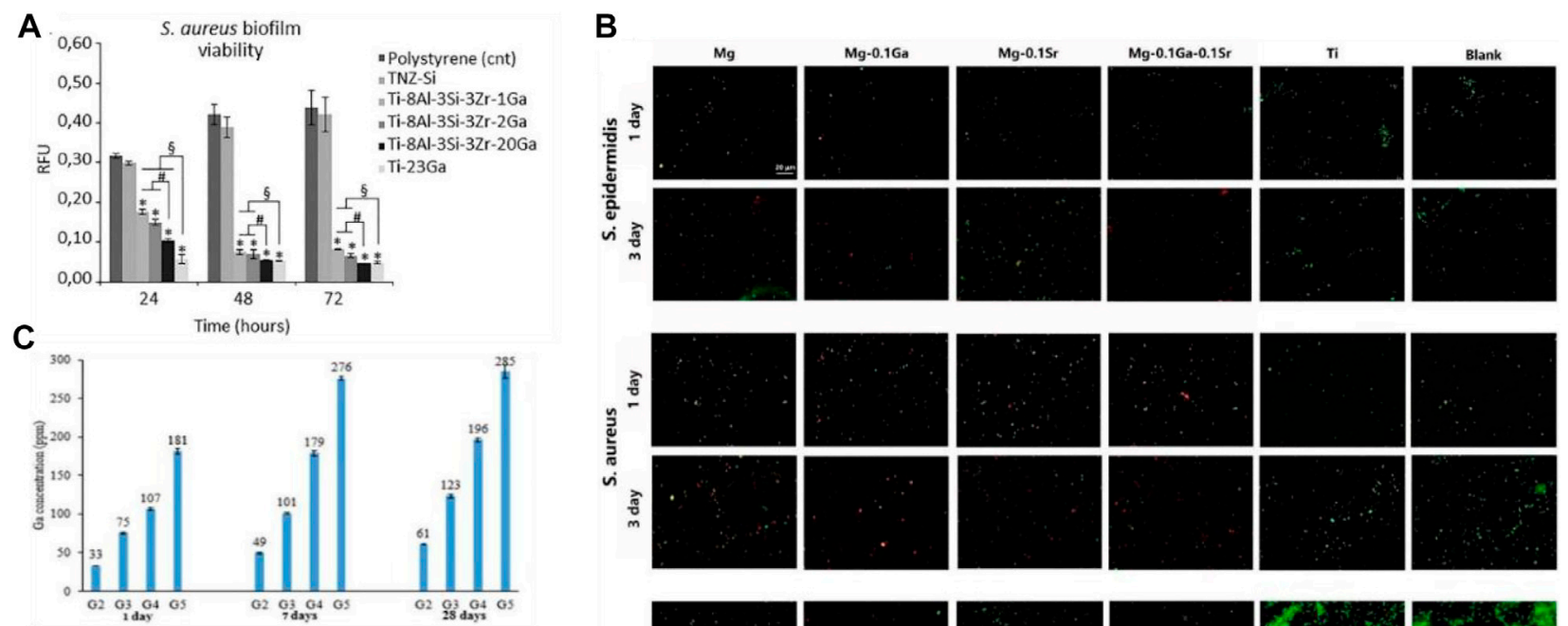

D
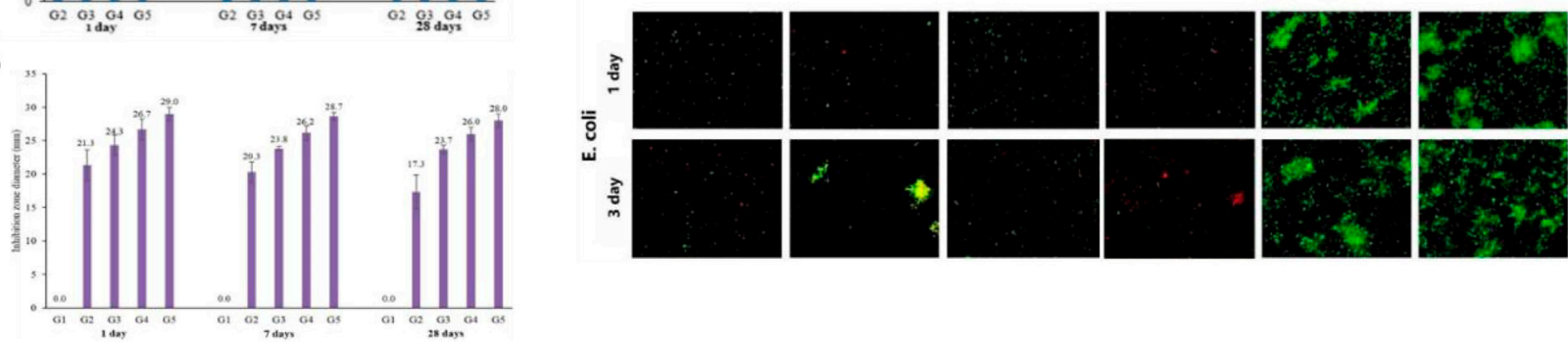

FIGURE 4 | (A) Antibacterial effect of metallurgical gallium additions to titanium alloys against S. aureus biofilm formation (Cochis et al., 2019). (B) Fluorescent images of biofilms formed by Staphylococcus epidermidis, S. aureus, and E. coli on pure Mg, Mg-0.1 Ga, Mg-0.1 Sr, Mg-0.1 Ga-0.1 Sr, and c.p. Ti surfaces at days 1 and 3; biofilms were detected through live-dead staining (Gao et al., 2019). (C) Accumulated concentration of gallium ions released from different borate glasses with increased gallium content $\left(0,2.5,5,10\right.$, and $15 \mathrm{Wt} \% \mathrm{Ga}$ ) after being immersed in deionized water for 1,7 , and 28 days at $37^{\circ} \mathrm{C}$ (Rahimnejad Yazdi et al., 2018). (D) Evaluation of long-time antibacterial activity of the borate glasses against $P$. aeruginosa after 1, 7, and 28 days of incubation; inhibition was determined by measuring inhibition zone diameters (Rahimnejad Yazdi et al., 2018).

preparation of gallium-loaded nanomaterials. The targeted accumulation of gallium in bacterial cells depends mainly on the formation of couplings with endogenous siderophores or hemes. Through the Trojan horse strategy, gallium is transported into bacterial cells with the help of the bacteria's own iron acquisition receptors. The antibacterial activities of common gallium-siderophores and galliumheme conjugates have been summarized by Kelson et al. (2013), including those of desferoxamine-gallium, Gaprotoporphyrin IX, Ga-deuteroporphyrin, Gamesoporphyrin, Ga-hematoporphyrin, Gaoctaethylporphyrin, and Ga-porphine. Among them, Gaprotoporphyrin IX, as a heme analogue, showed the best antibacterial effect and had a good bactericidal effect on both Gram-positive and Gram-negative bacteria for perturbing the metabolism of heme. It is worth noting that not all siderophores combined with an antibacterial agent show increased antibacterial activity (Frangipani et al., 2014).

Sanderson et al. (2020) synthesized a novel ciprofloxacinsiderophore antimicrobial (Figure 3A) by incorporating key design features of salmochelin, a stealth siderophore expressed by many Enterobacteriaceae; however, it decreased the uptake of gallium and antibacterial potency compared to ciprofloxacin alone both in iron replete and deplete conditions (Figures 3B,C). Frangipani et al. (2014) compared the antibacterial activity of several commonly used siderophore-gallium complexes with gallium nitrate alone, and the results were similar to those described above. Only the complex formed with the endogenous siderophore, the pyochelin-gallium complex, significantly potentiated the antibacterial activity of gallium ions, whereas those with ferrichrome, desferrioxamine, and pyoverdine, alleviated the antibacterial effect of gallium nitrate. These results suggest that the type of siderophore and the size and polar surface area of the corresponding conjugate remain significant challenges in the design of Trojan horse antimicrobials, which may prevent gallium from being recognized by receptors of the outer membrane.

In addition to gallium-ligand and gallium-iron/heme carriers, Lin et al. (2021) provided a new strategy: the active uptake of gallium by bubble-propelled Janus gallium/zinc micromotors that, at an acidic microenvironment, can increase the gallium content in bacteria (Figure 3D). Based on the same principle, Best et al. (2020) prepared a family of bioresponsive antibacterial 
nanomaterials based on gallium (III) and iron (III) cross-linked polysaccharide materials (Figure 3E), to which $P$. aeruginosa was specifically responsive, to improve the bioavailability of gallium ions.

\subsection{Construction of Gallium-Doped Alloys and Scaffold Composites}

Although gallium has a definite antibacterial effect, existing gallium-based drugs, including gallium nitrate, tend to quickly release gallium (III) in vivo, reaching the maximum concentration in an extremely short time and failing to exert an antibacterial effect. Opportunities for iatrogenic infections exist anytime, and it is particularly critical that the concentration of an antibacterial agent at infective sites is maintained above the MIC. The controlled and sustained release of antibacterial agents is of great significance for the prevention and treatment of clinically common implant-related infections and skin incision-related infections. In addition, gallium salts and gallium-based complexes are mostly administered intravenously or orally, while local treatments tend to be safer, which is of great clinical significance for local infection control.

Innovations in biomaterials, such as hydrogels and bioglasses, as well as improvements in manufacturing processes, such as coating technology, 3D printing technology, and metallurgy technology, make it possible for gallium-loaded scaffolds and alloys to be applied in the body as tissue engineering materials. In view of the low melting point $\left(15.5^{\circ} \mathrm{C}\right)$ of gallium and its similarity with aluminum, it is possible to microalloy gallium with other biocompatible metals. Cochis et al. (2019) investigated Ga-doped titanium alloys using metallurgical methods, and the results demonstrated that these alloys ensured long-lasting release of $\mathrm{Ga}$ (III) and strong antibacterial effects on multidrug-resistant $S$. aureus for at least 3 days, showing a high potential for the treatment of implant-related infections in orthopedics. After metallurgical addition of gallium, the antibacterial activity of titanium alloys was significantly improved compared with that of polystyrene, and the antibacterial activity could still be observed after 3 days. Although the antibacterial activity over longer periods of time was not studied, the effect would be expected to be good after observing the trend. In addition, with the increase in gallium content, the antibacterial activity of the alloy gradually improved; however, the mechanical properties of the titanium alloy might also be affected, making it necessary to further explore the optimal gallium loading amount (Figure 4A).

Similarly, through gallium-strontium microalloying, magnesium alloys (Gao et al., 2019) have also been shown to be effective in the treatment of osteomyelitis. Compared with titanium, magnesium is degradable under physiological conditions with certain advantages in the treatment of bone infections; moreover, magnesium allows for the sustained release of gallium (III). According to the observations from fluorescent imaging studies (Figure 4B), magnesium alloys combined with gallium almost eliminated $S$. aureus and E. coli after 3 days. The red fluorescence intensity of the Ga-containing magnesium alloy increased gradually and reached a maximum on the third day, indicating the slow-release effect of gallium ions. Besides, 3D printed gallium-based liquid metals such as eutectic gallium-indium alloys have also shown time-increasing bactericidal effects against Gram-positive bacteria (Li K. et al., 2021).

With the development of manufacturing technology and the constant updating of biological materials, an increasing number of materials are used as scaffolds to store antibacterial agents to achieve a slow release. Mesoporous bioactive glasses (Kurtuldu et al., 2021) have been widely applied in vivo in non-weight-bearing parts of the body such as the oral cavity, in orthopedics, and in skin tissues where they act as repair materials and drug-loading scaffolds (Mehrabi et al., 2020). Recently, bioglasses doped with gallium have been gradually used as antibacterial materials against bone defect infections (Wang et al., 2021a), caries infections (Siqueira et al., 2019; Song et al., 2019), and skin incision infections (Lapa et al., 2019). The in vitro ion release curves from these gallium-loaded complexes show that gallium can be continuously released for nearly $550 \mathrm{~h}$ and that the concentration of gallium ions can reach $20 \mathrm{ppm}$ on day 21 (Ciraldo et al., 2021), which may be attributed to the network structure and composition of the bioglass, especially to its calcium content (Keenan et al., 2017; Rahimnejad Yazdi et al., 2018).

Rahimnejad Yazdi et al. (2018) synthesized a gallium-doped zinc borate bioactive glass exhibiting a sustained and controlled release of gallium for at least 28 days. Interestingly, different gallium contents resulted in different gallium ion release curves (Figure 4C) and different antibacterial effects (Figure 4D). The cumulative concentrations of gallium (III) in all gallium-loaded bioglasses under a simulated body fluid environment increased gradually, and the highest gallium content reached $285 \mathrm{ppm}$ on day 28 . The controlled release of gallium ions was consistent with the sustained bacteriostatic activity against $P$. aeruginosa over 28 days. Other biomaterials, including phosphate glass (Lapa et al., 2020), hydroxyapatite (Pajor et al., 2020), PCL and hydrogel (Rastin et al., 2021), collagen (Xu et al., 2019), poly (4-hydroxybutyrate) (Muller et al., 2021), silk fibroin (Mehrabi et al., 2020), and Ca titanate (Rodriguez-Contreras et al., 2020), have also been proven to compound with gallium for a sustained release of gallium ions and to play an excellent bactericidal effect against common pathogens, such as E. coli, S. aureus, and P. aeruginosa, both in vivo and in vitro.

The successful synthesis of gallium-sustained release materials is of great clinical significance. On the one hand, hydrogel, bioceramics, and other materials with good biocompatibility can be directly used as tissue engineering scaffolds for the repair of infectious defects. On the other hand, chemical processes, such as electrophoretic deposition, thermochemical treatment (Rodriguez-Contreras et al., 2020), solid-state method (Pajor et al., 2020), radio-frequency magnetron sputtering (Stan et al., 2020), and gel/sol can form antibacterial coatings (Pajor et al., 2020; Rodriguez-Contreras et al., 2020; Stan et al., 2020; Almohandes et al., 2021; Centurion et al., 2021) containing 


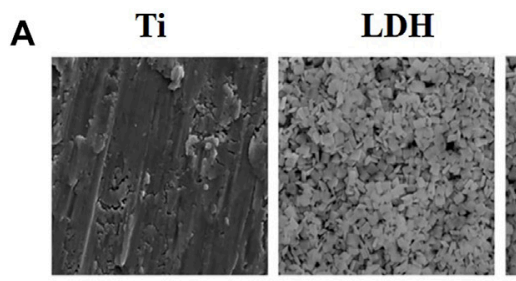

LDH250

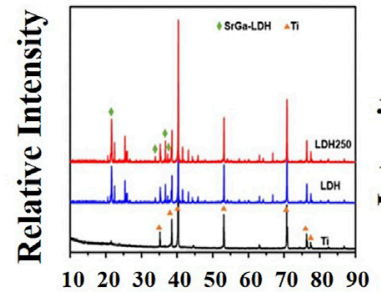

$2 \theta$ (degree)

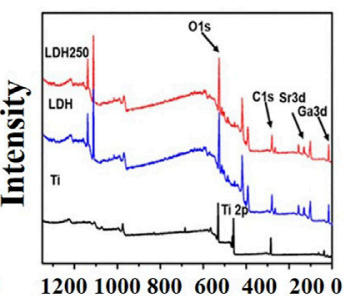

Binding energy (eV)

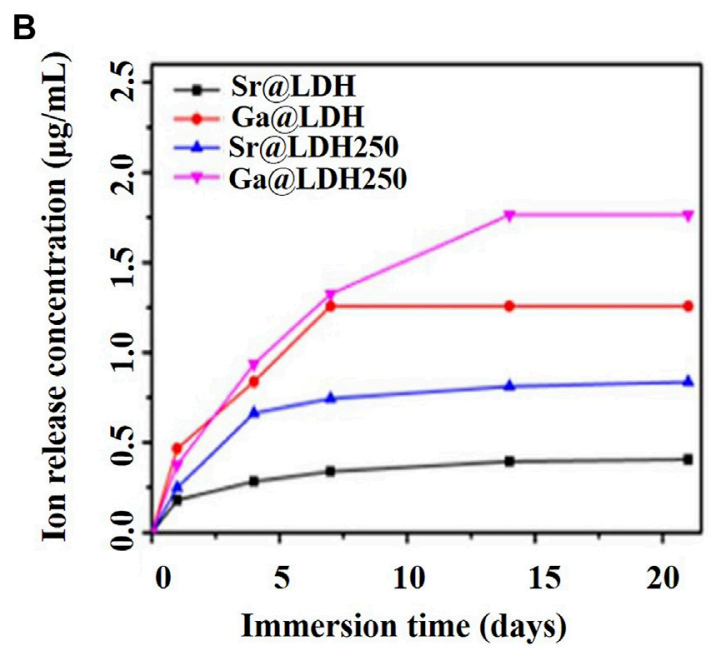

(B) The cumulative release of gallium and strontium ions from the layered double hydroxide (LDH) and layered double hydroxide calcined at $250^{\circ} \mathrm{C}(\mathrm{LDH} 250)$ was observed within 20 days of soaking in PBS solution ( $\mathrm{Li} \mathrm{K}$. et al., 2021$)$.

gallium on the surface of implants to prevent and treat iatrogenic infections. The controlled release of gallium by the above materials mainly benefits from their biodegradability, porous network structure, and adjustable porosity.

\subsection{Design of Gallium-Containing Layered Double Hydroxide}

LDHs are layered solids described by the general formula $\left[\mathrm{M}(\mathrm{II})_{1-\mathrm{x}} \mathrm{M}(\mathrm{III})_{\mathrm{x}}(\mathrm{OH})_{2}\right]\left(\mathrm{A}^{\mathrm{n}-}\right)_{\mathrm{x} / \mathrm{n}} \cdot \mathrm{nH} 2 \mathrm{O}$, where $\mathrm{M}(\mathrm{II})$ is a divalent cation, $\mathrm{M}(\mathrm{III})$ is a trivalent cation, and $\mathrm{A}^{\mathrm{n}-}$ represents the anions that balance the positive charges of the lamellae. LDHs have attracted considerable attention as drug release platforms and bone tissue engineering materials based on their excellent biocompatibility (Taviot-Guého et al., 2018). The region between layers can store a large amount of bioactive ions where drugs are released in a sustained manner. In addition, LDHs can also be combined with other materials such as hydroxyapatite without affecting their own structure (Donnadio et al., 2021), which is beneficial for realizing the multi-functionalization of galliumcontaining materials. Li K. et al. (2021) and Donnadio et al. (2021) constructed and characterized gallium (Ga)-strontium (Sr) layered double hydroxides (Figure 5A) and gallium (Ga)-zinc ( $\mathrm{Zn}$ ) layered double hydroxides, respectively, both of which exhibited sustained release of $\mathrm{Ga}$ ions. On day 21, the concentrations of $\mathrm{Ga}$ (III) released from LDH 250 and $\mathrm{LDH}$ reached almost 1.75 and $1.25 \mu \mathrm{g} / \mathrm{ml}$, respectively (Figure 5B).

\subsection{Synergistic Antimicrobial Effects Between Gallium and Other Antibacterial Agents}

Recently, the combination of multiple antibacterial agents to achieve enhanced antibacterial effects has become a research hotspot (Pormohammad \& Turner, 2020). With the excessive use of antibiotics and metal ions, bacteria gradually acquire drug resistance through horizontal gene transmission or gene mutation (Sutterlin et al., 2017). Some researchers have isolated bacterial strains that are resistant to gallium ions (Garcia-Contreras et al., 2013). The combination of two or more drugs with different antimicrobial mechanisms may reduce or delay the emergence of antimicrobial resistance by attacking different bacterial targets (Cottarel \& Wierzbowski, 2007; Fischbach, 2011). In addition, the combined use of multiple antibacterial agents can reduce the therapeutic dose and concentration of a single antibacterial agent, thus reducing toxicity and side reactions, increasing the treatment window, and improving biological safety (Harrison et al., 2008).

The diversity of existing antibacterial agents has promoted a diversity of combinations with gallium ions. Among them, the combination of traditional antibiotics and gallium-based antimicrobials has attracted considerable attention. Rezzoagli et al. (2020) evaluated the synergistic antibacterial effect of gallium ions in combination with four clinically common antibiotics (ciprofloxacin, colistin, meropenem, and tobramycin) using a $9 \times 9$ drug concentration matrix. The results showed that gallium ions not only restored the bactericidal effect of traditional antibiotics, but also reversed the drug resistance of resistant bacteria. A research conducted by Kang et al. (2021) demonstrated that tetracycline could inhibit the biosynthesis of the endogenous siderophore pyoverdine at concentrations lower than the MIC, thus enhancing the antibacterial activity of gallium nitrate both in vitro and in vivo. In other words, gallium ions could reduce the concentration of conventional antibiotics for treatment, allowing antibiotics to play a role in the treatment of resistant bacteria. In addition to gallium nitrate, the $\mathrm{Ga}$ (III)-based compounds mentioned above, including Ga-siderophores and Ga-porphyrin, were used as adjuvants of antibiotics for 

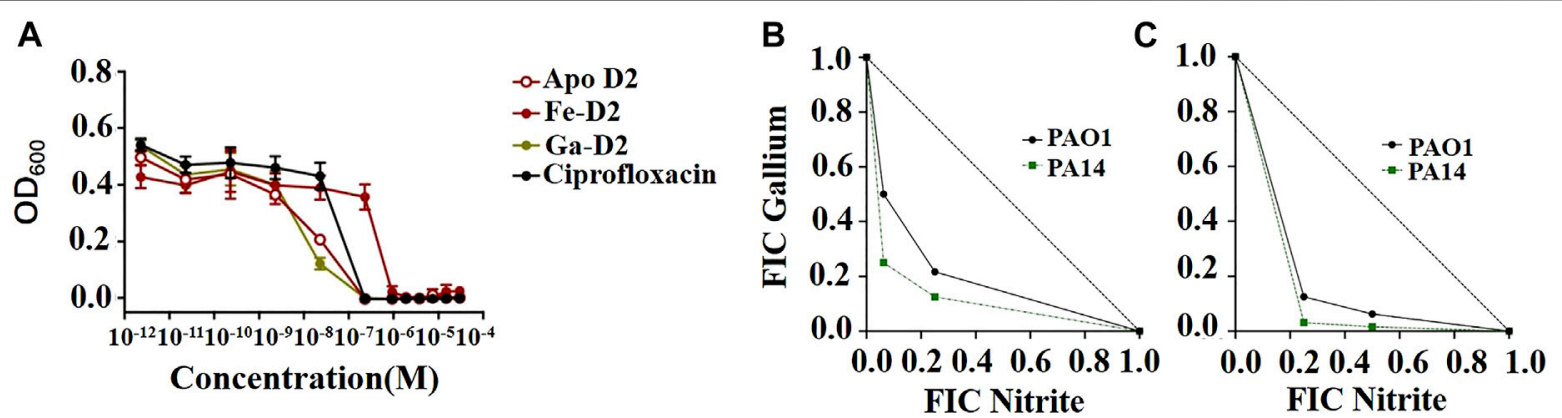

FIGURE 6 | (A) MIC assays using a gallium-based complexes of ciprofloxacin-functionalized desferrichrome (D2) against E. coli K12 indicated that the Ga-D2 complex has a greater antibacterial potential when compared to that of ciprofloxacin alone (Pandey et al., 2019). (B,C) Synergistic antibacterial activity between nitrite and $\mathrm{Ga}^{3+}$. The isobolograms show the results of checkerboard assays for $P$. aeruginosa PAO1 and PA14 showing the fractional inhibitory concentration (FICs) of the two compounds in combination under (B) aerobic and (C) anaerobic conditions (Zemke et al., 2020).

antibacterial purposes. Both gallium-porphyrin and galliumheme targeted the bacterial iron metabolism pathway because they were specifically and directly recognized and absorbed by bacterial membrane receptors. Therefore, gallium complexes bound to antibiotics entered bacterial cells, increasing antibiotic sensitivity, and playing a synergistic role. For example, protoporphyrin IX, which serves as a heme analogue, has been demonstrated to have enhanced antibacterial activity against several bacterial species by targeting cytochromes and interfering with cellular respiration (Hijazi et al., 2017).

Pandey et al. (2019) demonstrated that ciprofloxacinfunctionalized desferrichrome exhibited a MIC of $0.23 \mu \mathrm{M}$ for E. coli, in accordance with its parent fluoroquinolone antibiotic, and showed potent against $P$. aeruginosa, $S$. aureus, and $K$. pneumoniae with MICs of $3.8,0.94$, and $12.5 \mu \mathrm{M}$, respectively. The dose-response curve showed that the antibacterial effect of ciprofloxacin-functionalized gallium- desferrichrome conjugates was superior to that of ciprofloxacin alone (Figure 6A). In addition to using antibiotics directly, Qiao et al. (2021a) introduced PEG to further increase bacterial susceptibility to vancomycin, demonstrating excellent antibacterial activity.

Considering the excellent synergistic antibacterial effects of traditional antibiotics and gallium ions, combined antibacterial treatments with gallium and non-antibiotic antibacterial agents has also been explored. Akhtar et al. (2020) prepared a galliumchitosan complex and performed in vitro experiments that showed that the antibacterial rate of the complex against E. coli was above $90 \%$ compared with that of single chitosan. Qiao et al. (2021b) developed a triple combination strategy, as follows: 1) cationic guanidine moieties and short alkyl quaternary ammonium salts were chosen to destroy the bacterial membrane, 2) deferoxamine (DFO)-gallium conjugated to the above copolymer (namely the pGQ-DG complex) was used to disrupt iron metabolism, and 3) vancomycin (VAN) was finally added. The study demonstrated that the fractional inhibitory concentration index (FICI) of sub-MIC concentrations of pGQ-DG combined with VAN was 0.31 in $P$. aeruginosa, confirming their synergy-when FICI values are lower than 0.5 , there is a synergistic effect between the drugs tested (Yoon et al., 2006). However, no obvious synergistic effects were observed in E. coli between VAN and pGQ-DG. This indicates that the synergistic antibacterial effect between drugs is not absolute and that the synergistic effect will be either enhanced or weakened depending on the bacterial species. It is critical to find optimal synergistic antibacterial formulations for specific pathogens. In vivo experiments demonstrated that the three-drug combination had a strong synergistic effect and could achieve the same effect as colistin in the elimination of $P$. aeruginosa, simultaneously accelerating the healing of infected wounds.

Several studies investigated the antimicrobial synergies between different metal ions, and fractional inhibitory concentration and fractional bactericidal concentration assays were used to evaluate synergistic intensity (Yoon et al., 2006; Aziz, 2019; Vaidya et al., 2019; Pormohammad \& Turner, 2020). The results showed that silver ions, zinc ions, $\mathrm{Cd}$, Se, and $\mathrm{Ga}$ had good synergistic effects. According to Morales-de-Echegaray et al. (2020), the antibacterial activity of gallium-substituted hemoglobin combined with Ag nanoparticles showed multiple amplifications. In addition, antibacterial photodynamic treatment has also been used in combination with gallium to treat bacterial infections. In several studies, gallium-porphyrin, gallium-substituted hemoglobin, phthalocyanine, indocyanine green (ICG), and hollow titanium dioxide nanotubes were used as photosensitizers to couple with gallium (Morales-deEchegaray et al., 2020; Shisaka et al., 2019; Xie et al., 2021; Yang et al., 2020). Under near-infrared light irradiation, photosensitizers catalyze the production of reactive oxygen substances such as singlet oxygen which has membrane permeability and can cause irreversible oxidative damage to cell membranes, DNA, and lipids (Imlay, 2013). This synergistic mechanism may occur because gallium affects the activity of bacterial antioxidant enzymes by interfering with their iron metabolism, increasing the sensitivity of bacteria to oxidative stress; thus, the reactive oxygen species produced by the action of photosensitizers may promote the killing of bacteria.

Similarly, Zemke et al. (2020) combined nitrates and gallium, where nitrates served as nitric oxide donors-a type of reactive oxygen species-, to induce antibacterial activity against $P$. aeruginosa under both aerobic and anaerobic conditions 
(Figures 6B,C). Slate et al. (2021) used the sharp nanomorphology of non-metallic graphene and its derivatives to destroy bacterial cell membranes, they simultaneously used gallium that slowly released from graphene foam to interfere with bacterial iron metabolism, which also had a positive synergistic effect.

\section{CONCLUSION AND PROSPECTIVE VIEWS}

With the recent development of coordination chemistry, an increasing number of organic ligands have been developed to chelate gallium. Therefore, gallium-based compounds have enhanced solubility and improved bioavailability. The coating of biomaterials responsive to an infected microenvironment can greatly increase the gallium ion concentration at the infected site. In addition, further elucidation of the mechanism of gallium acquisition will provide the basis for targeted antibacterial therapy; simultaneously, the constant research on mesoporous materials, bioceramics, hydrogels, bacterial microenvironment-responsive materials, and coating technologies could provide new options for the modification and loading of gallium-based antibacterial agents to realize the sustained and controllable release of gallium (III) and greatly improve the antibacterial effect of this element.

Furthermore, the combined use of various antibacterial agents results in exciting synergistic antibacterial effects. At present, there is a variety of antibacterial drugs, including antibiotics, chitosan, antibacterial peptides, and metal ions, as well as complex antibacterial treatments, such as photothermal treatment, chemical dynamic treatment, photodynamic treatment, and physical destruction. All these antibacterial drugs and methods could be used in combination with gallium, and their combined antibacterial effects remain to be explored. The continuous optimization of the key factors affecting the antibacterial efficiency of gallium will provide the possibility for gallium to be used in the clinic.

However, gallium, as an antibacterial agent, also faces some challenges. Gallium has no indications for patients with specific pathological conditions. Due to its immunosuppressive effect, long-term use of gallium could lead to decreased immune capacity of the body, which is unfortunate for patients with immune deficiencies. In contrast, the antibacterial activity of gallium might be beneficial for patients with hemochromatosis and thalassemia, which cause pathological iron overload. Considering the susceptibility and severity of an infection in these patients, it would be of great clinical significance to

\section{REFERENCES}

Akhtar, M. A., Hadzhieva, Z., Dlouhý, I., and Boccaccini, A. R. (2020). Electrophoretic Deposition and Characterization of Functional Coatings Based on an Antibacterial Gallium (III)-chitosan Complex. Coatings 10 (5), 483. doi:10.3390/coatings 10050483 successfully use gallium-based antibacterial agents to treat such infections.

Although gallium ions, as multi-target antimicrobial agents, have been demonstrated to have definite and excellent bactericidal effects against pathogens that are resistant to traditional antibiotics, the potency of gallium-based antimicrobials is relatively lower than that of some existing antibacterial drugs. Gallium maltoate has an MIC of more than $250 \mu \mathrm{g} / \mathrm{ml}$ against $P$. aeruginosa, much higher than some clinical antibiotics, such as murepavadin ( $\mathrm{MIC}=2 \mu \mathrm{g} / \mathrm{ml}$ ) and colistin ( $\mathrm{MIC}=1 \mu \mathrm{g} / \mathrm{ml}$ ) (Ekkelenkamp et al., 2020; Piatek et al., 2020). Combination therapies with gallium-based antibacterial agents are expected to further reduce the concentration of gallium ions, so as to be better applied in the treatment of drug-resistant bacteria in the clinic. In addition, understanding the exact antibacterial mechanism of gallium ions remains a long way off. Although gallium has been demonstrated to play an antibacterial role by interrupting iron metabolism, there have been no reports on the proteins or enzymes on which gallium ions act. The identification of gallium ion targets is of great significance for improving gallium antibacterial effects and tackling drug resistance. More research is proposed to focus on the molecular mechanism of the antibacterial activity of gallium in the future. Finally, in recent years, the successful synthesis of various metal-organic frameworks, covalentorganic frameworks, hydrogen-bonded organic frameworks, and other emerging nanomaterials with ultra-high specific surface areas, satisfactory biocompatibility, biodegradability, and high density with uniformly distributed catalytic active sites has greatly promoted the development of antibacterial agents and enriched antimicrobial strategies. However, their combined use with gallium ions is rarely reported, and we believe that this direction possesses promising research prospects.

\section{AUTHOR CONTRIBUTIONS}

FL: writing the manuscript. $\mathrm{KH}, \mathrm{FL}$, and SY: revising and editing the manuscript. All authors contributed to the article and approved the submitted version.

\section{FUNDING}

This work was funded by the National Natural Science Foundation of China (81802178, 92068205 and 81871790), the Shanghai Science and Technology Development Fund (20QC1400800 and 21QA1405400).

Almohandes, A., Abrahamsson, I., Dahlén, G., and Berglundh, T. (2021). Effect of Biofilm Formation on Implant Abutments with an Anti-bacterial Coating: A Pre-clinical In Vivo Study. Clin. Oral Impl Res. 32 (6), 756-766. doi:10.1111/clr. 13745

Andrews, S. C., Robinson, A. K., and Rodríguez-Quiñones, F. (2003). Bacterial Iron Homeostasis. Fems Microbiol. Rev. 27, 215-237. doi:10.1016/s0168-6445(03) 00055-x 
Aziz, W. J. (2019). Synthesis of CdSe and CdSe:Ga Nanostructures for Antibacterial Application. Bull. Mater. Sci. 42 (4), 148. doi:10.1007/s12034-019-1830-4

Bériault, R., Hamel, R., Chenier, D., Mailloux, R. J., Joly, H., and Appanna, V. D. (2007). The Overexpression of NADPH-Producing Enzymes Counters the Oxidative Stress Evoked by Gallium, an Iron Mimetic. Biometals 20 (2), 165-176. doi:10.1007/s10534-006-9024-0

Best, M. G., Cunha-Reis, C., Ganin, A. Y., Sousa, A., Johnston, J., Oliveira, A. L., et al. (2020). Antimicrobial Properties of Gallium(III)- and Iron(III)-loaded Polysaccharides Affecting the Growth of Escherichia coli, Staphylococcus aureus, and Pseudomonas aeruginosa, In Vitro. ACS Appl. Bio Mater. 3 (11), 7589-7597. doi:10.1021/acsabm.0c00811

Bonchi, C., Imperi, F., Minandri, F., Visca, P., and Frangipani, E. (2014). Repurposing of Gallium-Based Drugs for Antibacterial Therapy. Biofactors 40 (3), 303-312. doi:10.1002/biof.1159

Britigan, B. E., Rasmussen, G. T., Olakanmi, O., and Cox, C. D. (2000). Iron Acquisition from Pseudomonas aeruginosa Siderophores by Human Phagocytes: an Additional Mechanism of Host Defense through Iron Sequestration? Infect. Immun. 68 (3), 1271-1275. doi:10.1128/IAI.68.3.12711275.2000

Centola, G., Xue, F., and Wilks, A. (2020). Metallotherapeutics Development in the Age of Iron-Clad Bacteria. Metallomics 12 (12), 1863-1877. doi:10.1039/ $\mathrm{d} 0 \mathrm{mt} 00206 \mathrm{~b}$

Centurion, F., Namivandi-Zangeneh, R., Flores, N., Tajik, M., Merhebi, S., Abbasi, R., et al. (2021). Liquid Metal-Triggered Assembly of Phenolic Nanocoatings with Antioxidant and Antibacterial Properties. ACS Appl. Nano Mater. 4 (3), 2987-2998. doi:10.1021/acsanm.1c00125

Choi, S.-r., Britigan, B. E., Moran, D. M., and Narayanasamy, P. (2017). Gallium Nanoparticles Facilitate Phagosome Maturation and Inhibit Growth of Virulent Mycobacterium tuberculosis in Macrophages. PLoS One 12 (5), e0177987. doi:10.1371/journal.pone.0177987

Choi, S.-r., Britigan, B. E., and Narayanasamy, P. (2019). Dual Inhibition of Klebsiella pneumoniae and Pseudomonas aeruginosa Iron Metabolism Using Gallium Porphyrin and Gallium Nitrate. ACS Infect. Dis. 5 (9), 1559-1569. doi:10.1021/acsinfecdis.9b00100

Ciraldo, F. E., Arango-Ospina, M., Goldmann, W. H., Beltrán, A. M., Detsch, R., Gruenewald, A., et al. (2021). Fabrication and Characterization of Ag- and Gadoped Mesoporous Glass-coated Scaffolds Based on Natural marine Sponges with Improved Mechanical Properties. J. Biomed. Mater. Res. 109 (8), 1309-1327. doi:10.1002/jbm.a.37123

Cochis, A., Azzimonti, B., Chiesa, R., Rimondini, L., and Gasik, M. (2019). Metallurgical Gallium Additions to Titanium Alloys Demonstrate a strong Time-Increasing Antibacterial Activity without Any Cellular Toxicity. ACS Biomater. Sci. Eng. 5 (6), 2815-2820. doi:10.1021/acsbiomaterials.9b00147

Cottarel, G., and Wierzbowski, J. (2007). Combination Drugs, an Emerging Option for Antibacterial Therapy. Trends Biotechnol. 25 (12), 547-555. doi:10.1016/j. tibtech.2007.09.004

Donnadio, A., Bini, M., Centracchio, C., Mattarelli, M., Caponi, S., Ambrogi, V., et al. (2021). Bioinspired Reactive Interfaces Based on Layered Double Hydroxides-Zn Rich Hydroxyapatite with Antibacterial Activity. ACS Biomater. Sci. Eng. 7 (4), 1361-1373. doi:10.1021/acsbiomaterials.0c01643

Duffin, R. N., Blair, V. L., Kedzierski, L., and Andrews, P. C. (2020). Alkyl Gallium(III) Quinolinolates: a New Class of Highly Selective Antileishmanial Agents. Eur. J. Med. Chem. 186, 111895. doi:10.1016/j.ejmech. 2019.111895

Ekkelenkamp, M. B., Cantón, R., Díez-Aguilar, M., Tunney, M. M., Gilpin, D. F., Bernardini, F., et al. (2020). Susceptibility of Pseudomonas aeruginosa Recovered from Cystic Fibrosis Patients to Murepavadin and 13 Comparator Antibiotics. Antimicrob. Agents Chemother. 64 (2), e01541-19. doi:10.1128/AAC.01541-19

El-Habeeb, A. A., and Refat, M. S. (2019). Synthesis, Structure Interpretation, Antimicrobial and Anticancer Studies of Tranexamic Acid Complexes towards Ga(III), W(VI), Y(III) and Si(IV) Metal Ions. J. Mol. Struct. 1175, 65-72. doi:10. 1016/j.molstruc.2018.07.099

Enyedy, É. A., Petrasheuskaya, T. V., Kiss, M. A., Wernitznig, D., Wenisch, D., Keppler, B. K., et al. (2021). Complex Formation of an Estrone-Salicylaldehyde Semicarbazone Hybrid with Copper(II) and Gallium(III): Solution Equilibria and Biological Activity. J. Inorg. Biochem. 220, 111468. doi:10.1016/j.jinorgbio. 2021.111468
Fischbach, M. A. (2011). Combination Therapies for Combating Antimicrobial Resistance. Curr. Opin. Microbiol. 14 (5), 519-523. doi:10.1016/j.mib.2011. 08.003

Frangipani, E., Bonchi, C., Minandri, F., Imperi, F., and Visca, P. (2014). Pyochelin Potentiates the Inhibitory Activity of Gallium on Pseudomonas aeruginosa. Antimicrob. Agents Chemother. 58 (9), 5572-5575. doi:10.1128/AAC.03154-14

Gao, Z., Song, M., Liu, R.-L., Shen, Y., Ward, L., Cole, I., et al. (2019). Improving In Vitro and In Vivo Antibacterial Functionality of Mg Alloys through Microalloying with Sr and Ga. Mater. Sci. Eng. C 104, 109926. doi:10.1016/j.msec. 2019.109926

García-Contreras, R., Lira-Silva, E., Jasso-Chávez, R., Hernández-González, I. L., Maeda, T., Hashimoto, T., et al. (2013). Isolation and Characterization of Gallium Resistant Pseudomonas aeruginosa Mutants. Int. J. Med. Microbiol. 303 (8), 574-582. doi:10.1016/j.ijmm.2013.07.009

Greenfield, T. J., Julve, M., and Doyle, R. P. (2019). Exploring the Biological, Catalytic, and Magnetic Properties of Transition Metal Coordination Complexes Incorporating Pyrophosphate. Coord. Chem. Rev. 384, 37-64. doi:10.1016/j.ccr.2018.12.011

Halwani, M., Yebio, B., Suntres, Z. E., Alipour, M., Azghani, A. O., and Omri, A. (2008). Co-encapsulation of Gallium with Gentamicin in Liposomes Enhances Antimicrobial Activity of Gentamicin against Pseudomonas aeruginosa. J. Antimicrob. Chemother. 62 (6), 1291-1297. doi:10.1093/jac/dkn422

Harrison, J. J., Turner, R. J., Joo, D. A., Stan, M. A., Chan, C. S., Allan, N. D., et al. (2008). Copper and Quaternary Ammonium Cations Exert Synergistic Bactericidal and Antibiofilm Activity against Pseudomonas aeruginosa. Antimicrob. Agents Chemother. 52 (8), 2870-2881. doi:10. 1128/AAC.00203-08

Hijazi, S., Visca, P., and Frangipani, E. (2017). Gallium-protoporphyrin IX Inhibits Pseudomonas aeruginosa Growth by Targeting Cytochromes. Front. Cell. Infect. Microbiol. 7, 12. doi:10.3389/fcimb.2017.00012

Imlay, J. A. (2013). The Molecular Mechanisms and Physiological Consequences of Oxidative Stress: Lessons from a Model Bacterium. Nat. Rev. Microbiol. 11 (7), 443-454. doi:10.1038/nrmicro3032

Kaneko, Y., Thoendel, M., Olakanmi, O., Britigan, B. E., and Singh, P. K. (2007). The Transition Metal Gallium Disrupts Pseudomonas aeruginosa Iron Metabolism and Has Antimicrobial and Antibiofilm Activity. J. Clin. Invest. 117 (4), 877-888. doi:10.1172/JCI30783

Kang, D., and Kirienko, N. V. (2018). Interdependence between Iron Acquisition and Biofilm Formation in Pseudomonas aeruginosa. J. Microbiol. 56 (7), 449-457. doi:10.1007/s12275-018-8114-3

Kang, D., Revtovich, A. V., Deyanov, A. E., and Kirienko, N. V. (2021). Pyoverdine Inhibitors and Gallium Nitrate Synergistically Affect Pseudomonas aeruginosa. mSphere 6, e0040121. doi:10.1128/mSphere. 00401-21

Keenan, T. J., Placek, L. M., Hall, M. M., and Wren, A. W. (2017). Antibacterial and Antifungal Potential of Ga-bioactive Glass and Ga-bioactive Glass/ polymeric Hydrogel Composites. J. Biomed. Mater. Res. 105 (5), 1102-1113. doi:10.1002/jbm.b.33655

Kelson, A. B., Carnevali, M., and Truong-Le, V. (2013). Gallium-based Antiinfectives: Targeting Microbial Iron-Uptake Mechanisms. Curr. Opin. Pharmacol. 13 (5), 707-716. doi:10.1016/j.coph.2013.07.001

Kircheva, N., and Dudev, T. (2021). Competition between Abiogenic and Biogenic Metal Cations in Biological Systems: Mechanisms of Gallium's Anticancer and Antibacterial Effect. J. Inorg. Biochem. 214, 111309. doi:10.1016/j.jinorgbio. 2020.111309

Kurtuldu, F., Mutlu, N., Michálek, M., Zheng, K., Masar, M., Liverani, L., et al. (2021). Cerium and Gallium Containing Mesoporous Bioactive Glass Nanoparticles for Bone Regeneration: Bioactivity, Biocompatibility and Antibacterial Activity. Mater. Sci. Eng. C 124, 112050. doi:10.1016/j.msec. 2021.112050

Łapa, A., Cresswell, M., Campbell, I., Jackson, P., Goldmann, W. H., Detsch, R., et al. (2020). Gallium- and Cerium-Doped Phosphate Glasses with Antibacterial Properties for Medical Applications. Adv. Eng. Mater. 22 (9), 1901577. doi:10.1002/adem.201901577

Łapa, A., Cresswell, M., Campbell, I., Jackson, P., Goldmann, W. H., Detsch, R., et al. (2019). Ga and Ce Ion-Doped Phosphate Glass Fibres with Antibacterial Properties and Their Composite for Wound Healing Applications. J. Mater. Chem. B 7 (44), 6981-6993. doi:10.1039/c9tb00820a 
Lessa, J. A., Parrilha, G. L., and Beraldo, H. (2012). Gallium Complexes as New Promising Metallodrug Candidates. Inorg. Chim. Acta 393, 53-63. doi:10.1016/ j.ica.2012.06.003

Levaditi, C., Bardet, J., Tchakirian, A., and Vaisman, A. (1931). Therapeutic Properties of Gallium in Syphilis and Trypanosomiasis. C. R. Acad. Bulg. Sci. 192 (18), 1142-1143.

Leyland-Jones, B. (2003). Treatment of Cancer-Related Hypercalcemia: the Role of Gallium Nitrate. Semin. Oncol. 30, 13-19. doi:10.1016/s00937754(03)00171-4

Li, K., Tian, H., Guo, A., Jin, L., Chen, W., and Tao, B. (2021a). Gallium (Ga)strontium (Sr) Layered Double Hydroxide Composite Coating on Titanium Substrates for Enhanced Osteogenic and Antibacterial Abilities. J. Biomed. Mater. Res 110 (2), 273-286. doi:10.1002/jbm.a.37284

Li, L., Chang, H., Yong, N., Li, M., Hou, Y., and Rao, W. (2021b). Superior Antibacterial Activity of Gallium Based Liquid Metals Due to Ga3+ Induced Intracellular ROS Generation. J. Mater. Chem. B 9 (1), 85-93. doi:10.1039/d0tb00174k

Lin, Z., Gao, C., Wang, D., and He, Q. (2021). Bubble-Propelled Janus Gallium/ Zinc Micromotors for the Active Treatment of Bacterial Infections. Angew. Chem. Int. Ed. 60 (16), 8750-8754. doi:10.1002/anie.202016260

Mehrabi, T., Mesgar, A. S., and Mohammadi, Z. (2020). Bioactive Glasses: A Promising Therapeutic Ion Release Strategy for Enhancing Wound Healing. ACS Biomater. Sci. Eng. 6 (10), 5399-5430. doi:10.1021/acsbiomaterials. 0c00528

Morales-de-Echegaray, A. V., Lin, L., Sivasubramaniam, B., Yermembetova, A., Wang, Q., Abutaleb, N. S., et al. (2020). Antimicrobial Photodynamic Activity of Gallium-Substituted Haemoglobin on Silver Nanoparticles. Nanoscale 12 (42), 21734-21742. doi:10.1039/c9nr09064a

Müller, A., Fessele, C., Zuber, F., Rottmar, M., Maniura-Weber, K., Ren, Q., et al. (2021). Gallium Complex-Functionalized P4HB Fibers: a Trojan Horse to Fight Bacterial Infection. ACS Appl. Bio Mater. 4 (1), 682-691. doi:10.1021/acsabm. 0c01221

Nielsen, I. G., Sommer, S., Dippel, A.-C., Skibsted, J., and Iversen, B. B. (2021). Pair Distribution Function and 71Ga NMR Study of Aqueous Ga3+ Complexes. Chem. Sci. 12 (43), 14420-14431. doi:10.1039/d1sc05190c

Ning, L. G., Kang, E.-T., Wang, Y. B., Hu, X. F., and Xu, L. Q. (2018). Recent Developments in Controlled Release of Antibiotics. Cpd 24 (8), 911-925. doi:10. 2174/1381612824666180315094947

Pajor, K., Pajchel, Ł., Zgadzaj, A., Piotrowska, U., and Kolmas, J. (2020). Modifications of Hydroxyapatite by Gallium and Silver IonsPhysicochemical Characterization, Cytotoxicity and Antibacterial Evaluation. Ijms 21 (14), 5006. doi:10.3390/ijms21145006

Pandey, A., Savino, C., Ahn, S. H., Yang, Z., Van Lanen, S. G., and Boros, E. (2019). Theranostic Gallium Siderophore Ciprofloxacin Conjugate with Broad Spectrum Antibiotic Potency. J. Med. Chem. 62 (21), 9947-9960. doi:10. 1021/acs.jmedchem.9b01388

Piatek, M., Griffith, D. M., and Kavanagh, K. (2020). Quantitative Proteomic Reveals Gallium Maltolate Induces an Iron-Limited Stress Response and Reduced Quorum-sensing in Pseudomonas aeruginosa. J. Biol. Inorg. Chem. 25 (8), 1153-1165. doi:10.1007/s00775-020-01831-x

Pormohammad, A., and Turner, R. J. (2020). Silver Antibacterial Synergism Activities with Eight Other Metal(loid)-Based Antimicrobials against Escherichia coli, Pseudomonas aeruginosa, and Staphylococcus aureus. Antibiotics 9 (12), 853. doi:10.3390/antibiotics 9120853

Qiao, J., Liu, Z., Cui, S., Nagy, T., and Xiong, M. P. (2021). Synthesis and Evaluation of an Amphiphilic Deferoxamine:gallium-Conjugated Cationic Random Copolymer against a Murine Wound Healing Infection Model of Pseudomonas aeruginosa. Acta Biomater. 126, 384-393. doi:10.1016/j.actbio. 2021.03.005

Qiao, J., Purro, M., Liu, Z., and Xiong, M. P. (2021). Effects of Polyethyelene Glycol-Desferrioxamine:gallium Conjugates on Pseudomonas aeruginosa Outer Membrane Permeability and Vancomycin Potentiation. Mol. Pharmaceutics 18 (2), 735-742. doi:10.1021/acs. molpharmaceut.0c00820

Rahimnejad Yazdi, A., Torkan, L., Stone, W., and Towler, M. R. (2018). The Impact of Gallium Content on Degradation, Bioactivity, and Antibacterial Potency of Zinc Borate Bioactive Glass. J. Biomed. Mater. Res. 106 (1), 367-376. doi:10. $1002 / j b m . b .33856$
Rastin, H., Ramezanpour, M., Hassan, K., Mazinani, A., Tung, T. T., Vreugde, S., et al. (2021). 3D Bioprinting of a Cell-Laden Antibacterial Polysaccharide Hydrogel Composite. Carbohydr. Polym. 264, 117989. doi:10.1016/j.carbpol. 2021.117989

Rezzoagli, C., Archetti, M., Mignot, I., Baumgartner, M., and Kümmerli, R. (2020). Combining Antibiotics with Antivirulence Compounds Can Have Synergistic Effects and Reverse Selection for Antibiotic Resistance in Pseudomonas aeruginosa. PLoS. Biol. 18 (8), e3000805. doi:10.1371/journal.pbio.3000805

Rodríguez-Contreras, A., Torres, D., Guillem-Marti, J., Sereno, P., Ginebra, M. P., Calero, J. A., et al. (2020). Development of Novel Dual-Action Coatings with Osteoinductive and Antibacterial Properties for 3D-Printed Titanium Implants. Surf. Coat. Technology 403, 126381. doi:10.1016/j.surfcoat.2020. 126381

Roope, L. S. J., Smith, R. D., Pouwels, K. B., Buchanan, J., Abel, L., Eibich, P., et al. (2019). The challenge of Antimicrobial Resistance: what Economics Can Contribute. Science 364 (6435), 41. doi:10.1126/science.aau4679

Sanderson, T. J., Black, C. M., Southwell, J. W., Wilde, E. J., Pandey, A., Herman, R. et al. (2020). A Salmochelin S4-Inspired Ciprofloxacin Trojan Horse Conjugate. ACS Infect. Dis. 6 (9), 2532-2541. doi:10.1021/acsinfecdis.0c00568

Seyoum, Y., Baye, K., and Humblot, C. (2021). Iron Homeostasis in Host and Gut Bacteria - a Complex Interrelationship. Gut Microbes 13 (1), e1874855. doi:10. 1080/19490976.2021.1874855

Shao, W., Liu, H., Wang, S., Wu, J., Huang, M., Min, H., et al. (2016). Controlled Release and Antibacterial Activity of Tetracycline Hydrochloride-Loaded Bacterial Cellulose Composite Membranes. Carbohydr. Polym. 145, 114-120. doi:10.1016/j.carbpol.2016.02.065

Shisaka, Y., Iwai, Y., Yamada, S., Uehara, H., Tosha, T., Sugimoto, H., et al. (2019). Hijacking the Heme Acquisition System of Pseudomonas aeruginosa for the Delivery of Phthalocyanine as an Antimicrobial. ACS Chem. Biol. 14, 1637-1642. doi:10.1021/acschembio.9b00373

Siqueira, R. L., Alves, P. F. S., da Silva Moraes, T., Casemiro, L. A., da Silva, S. N., Peitl, O., et al. (2019). Cation-doped Bioactive Ceramics: In Vitro Bioactivity and Effect against Bacteria of the Oral Cavity. Ceramics Int. 45 (7), 9231-9244. doi:10.1016/j.ceramint.2019.02.001

Slate, A. J., Karaky, N., Crowther, G. S., Butler, J. A., Banks, C. E., McBain, A. J., et al. (2021). Graphene Matrices as Carriers for Metal Ions against Antibiotic Susceptible and Resistant Bacterial Pathogens. Coatings 11 (3), 352. doi:10. 3390/coatings 11030352

Song, H.-K., Yoo, K.-H., Yoon, S.-Y., Na, H. S., Chung, J., Son, W.-S., et al. (2019). In Vitro effect of Gallium-Doped Bioactive Glass on Enamel Antidemineralization and Bond Strength of Orthodontic Resins. Appl. Sci. 9 (22), 4918. doi:10.3390/app9224918

Stan, G. E., Tite, T., Popa, A.-C., Chirica, I. M., Negrila, C. C., Besleaga, C., et al. (2020). The Beneficial Mechanical and Biological Outcomes of Thin CopperGallium Doped Silica-Rich Bio-Active Glass Implant-type Coatings. Coatings 10 (11), 1119. doi:10.3390/coatings10111119

Sütterlin, S., Dahlö, M., Tellgren-Roth, C., Schaal, W., and Melhus, A. (2017). High Frequency of Silver Resistance Genes in Invasive Isolates of Enterobacter and Klebsiella Species. J. Hosp. Infect. 96 (3), 256-261. doi:10.1016/j.jhin.2017.04.017

Taviot-Guého, C., Prévot, V., Forano, C., Renaudin, G., Mousty, C., and Leroux, F. (2018). Tailoring Hybrid Layered Double Hydroxides for the Development of Innovative Applications. Adv. Funct. Mater. 28 (27), 1703868. doi:10.1002/ adfm. 201703868

Vaidya, M., McBain, A. J., Banks, C. E., and Whitehead, K. A. (2019). Single and Combined Antimicrobial Efficacies for Nine Metal Ion Solutions against Klebsiella pneumoniae, Acinetobacter Baumannii and Enterococcus Faecium. Int. Biodeterioration Biodegradation 141, 39-43. doi:10.1016/j.ibiod.2018. 06.017

Wang, M., Yang, Y., Chi, G., Yuan, K., Zhou, F., Dong, L., et al. (2021). A 3D Printed Ga Containing Scaffold with Both Anti-infection and Bone Homeostasis-Regulating Properties for the Treatment of Infected Bone Defects. J. Mater. Chem. B 9 (23), 4735-4745. doi:10.1039/d1tb00387a

Wang, Z., Li, J., Benin, B. M., Yu, B., Bunge, S. D., Abeydeera, N., et al. (2021). Lipophilic Ga Complex with Broad-Spectrum Antimicrobial Activity and the Ability to Overcome Gallium Resistance in Both Pseudomonas aeruginosa and Staphylococcus aureus. J. Med. Chem. 64 (13), 9381-9388. doi:10.1021/acs. jmedchem.1c00656 
Wilson, B. R., Bogdan, A. R., Miyazawa, M., Hashimoto, K., and Tsuji, Y. (2016). Siderophores in Iron Metabolism: from Mechanism to Therapy Potential. Trends Mol. Med. 22 (12), 1077-1090. doi:10.1016/j.molmed.2016.10.005

Xie, T., Qi, Y., Li, Y., Zhang, F., Li, W., Zhong, D., et al. (2021). Ultrasmall Ga-ICG Nanoparticles Based Gallium ion/photodynamic Synergistic Therapy to Eradicate Biofilms and Against Drug-Resistant Bacterial Liver Abscess. Bioact. Mater. 6 (11), 3812-3823. doi:10.1016/j.bioactmat.2021.03.032

Xu, Z., Chen, X., Tan, R., She, Z., Chen, Z., and Xia, Z. (2019). Preparation and Characterization of a Gallium-Loaded Antimicrobial Artificial Dermal Scaffold. Mater. Sci. Eng. C 105, 110063. doi:10.1016/j.msec.2019.110063

Yang, J., Wang, C., Liu, X., Yin, Y., Ma, Y., Gao, Y., et al. (2020). GalliumCarbenicillin Framework Coated Defect-Rich Hollow TiO2 as a Photocatalyzed Oxidative Stress Amplifier against Complex Infections. Adv. Funct. Mater. 30 (43), 2004861. doi:10.1002/adfm.202004861

Yoon, S. S., Coakley, R., Lau, G. W., Lymar, S. V., Gaston, B., Karabulut, A. C., et al. (2006). Anaerobic Killing of Mucoid Pseudomonas aeruginosa by Acidified Nitrite Derivatives under Cystic Fibrosis Airway Conditions. J. Clin. Invest. 116 (2), 436-446. doi:10.1172/jci24684

Young, M., Ozcan, A., Lee, B., Maxwell, T., Andl, T., Rajasekaran, P., et al. (2019). $\mathrm{N}$-acetyl Cysteine Coated Gallium Particles Demonstrate High Potency against Pseudomonas aeruginosa PAO1. Pathogens 8 (3), 120. doi:10.3390/ pathogens 8030120

Zemke, A. C., Madison, C. J., Kasturiarachi, N., Pearce, L. L., and Peterson, J. (2020). Antimicrobial Synergism toward Pseudomonas aeruginosa by Gallium(III) and Inorganic Nitrite. Front. Microbiol. 11, 2113. doi:10.3389/ fmicb.2020.02113

Zeng, J., Wu, L., Liu, Z., Lv, Y., Feng, J., Wang, W., et al. (2021). Gain-of-Function Mutations in Acid Stress Response ( evgS ) Protect Escherichia coli from Killing by Gallium Nitrate, an Antimicrobial Candidate. Antimicrob. Agents Chemother. 65 (3), e01595-20. doi:10.1128/AAC.01595-20

Zhang, Y., Pan, X., Wang, L., and Chen, L. (2021). Iron Metabolism in Pseudomonas aeruginosa Biofilm and the Involved Iron-Targeted Antibiofilm Strategies. J. Drug Target. 29 (3), 249-258. doi:10.1080/1061186x. 2020.1824235

Zhang, Z., Tang, J., Wang, H., Xia, Q., Xu, S., and Han, C. C. (2015). Controlled Antibiotics Release System through Simple Blended Electrospun Fibers for Sustained Antibacterial Effects. ACS Appl. Mater. Inter. 7 (48), 26400-26404. doi:10.1021/ acsami.5b09820

Conflict of Interest: The authors declare that the research was conducted in the absence of any commercial or financial relationships that could be construed as a potential conflict of interest.

Publisher's Note: All claims expressed in this article are solely those of the authors and do not necessarily represent those of their affiliated organizations, or those of the publisher, the editors and the reviewers. Any product that may be evaluated in this article, or claim that may be made by its manufacturer, is not guaranteed or endorsed by the publisher.

Copyright (c) $2022 \mathrm{Li}$, Liu, Huang and Yang. This is an open-access article distributed under the terms of the Creative Commons Attribution License (CC BY). The use, distribution or reproduction in other forums is permitted, provided the original author(s) and the copyright owner(s) are credited and that the original publication in this journal is cited, in accordance with accepted academic practice. No use, distribution or reproduction is permitted which does not comply with these terms. 